\title{
Os Mecanismos de Indução ao Cumprimento do Direito Internacional à Luz da Teoria Realista das Relações Internacionais
}

\author{
International Legal Compliance Based on Realist Paradigm of International \\ Relations
}

Fernando Lopes Ferraz Elias ${ }^{1}$

${ }^{1}$ Centro Universitário de Brasília (UniCEUB), Brasilia, DF, Brasil

\begin{abstract}
Resumo: Há uma carência de pesquisa acadêmica sobre o direito internacional com ferramentas metodológicas interdisciplinares, particularmente sobre o cumprimento do direito internacional a partir das teorias das relações internacionais. Diante disso, buscou-se analisar o fenômeno do cumprimento do direito internacional, conforme os argumentos centrais do paradigma realista das relações internacionais. Constatou-se que, para o realismo, o cumprimento do direito internacional depende do nível de coerção de seus mecanismos determinados pelas relações de poder e pelas assimetrias das relações internacionais.
\end{abstract}

Palavras-chave: Mecanismos de Indução ao Cumprimento do Direito Internacional. Teorias das Relações Internacionais. Realismo.

\begin{abstract}
There is a lack of academic research on international law with interdisciplinary methodological tools, particularly on international legal compliance from the theories of international relations. In view of this, we sought to analyze the phenomenon of the international legal compliance, according to the central arguments of the realist paradigm of international relations. It was observed that for realism the international legal compliance depends on the level of coercion of its mechanisms determined by the relations of power and the asymmetries of international relations.
\end{abstract}

Keywords: International Legal Compliance. International Relations Theories. Realism.

Recebido em: 06/06/2018

Revisado em: 03/10/2018

Aprovado em: 28/02/2019 


\section{Introdução}

O realismo, o mais antigo dos paradigmas, sempre duvidou da capacidade do direito internacional de regular as relações internacionais. Para os realistas, há uma relação dialética entre cooperação e conflito, o que torna simplesmente ilusório um direito sem mecanismos coercitivos e leva os estudos dos acadêmicos dessa teoria a abdicarem de aspirações normativas em prol da descrição positiva da realidade. Um comportamento cético em relação ao direito internacional que propugna pelas preocupações descritivas em detrimento de referências jurídicas.

Por meio de atores estatais e de fatores materiais, preponderantemente, o realismo conclui que as relações de poder determinam as relações internacionais, ou seja, as relações internacionais são traduzidas em termos de "equilíbrio de poder". Destarte, o poder é a variável básica independente da política internacional, e dele dependem a elaboração e o cumprimento do direito internacional.

Consequentemente, não há que se falar em uma força causal normativa independente sobre o comportamento internacional dos Estados, senão de uma lógica instrumental de custos e benefícios, diante da qual o direito internacional é um mero epifenômeno. Fora dessa lógica, os mecanismos de indução ao direito internacional não fazem sentido, dentro dela, a coerção induz o cumprimento do direito internacional, a partir de incentivos pelo cumprimento das normas internacionais e sanções (ou ameaça de sanções) pela sua violação. Dessa maneira, a coercibilidade dos mecanismos é diretamente proporcional à indução ao cumprimento das normas internacionais.

\section{Direito Internacional na Teoria Realista das Relações Inter- nacionais}

O realismo "clássico", a teoria dominante das relações internacionais por mais de dois mil anos, cuja origem remonta a Tucídides (2001), 
foi articulado por pensadores como Nicolau Maquiavel $(2011)^{1}$ e Thomas Hobbes (2003), e marcado pela proeminência do poder no cenário internacional, o que explica a escassez de trabalho empírico sobre o direito internacional (BOYLE, 1985, p. 3-16; GINSBURG; SHAFFER, 2009, p. 1).

O fracasso da Liga das Nações ${ }^{2}$ corroborou o pensamento realista calcado em políticas de poder. A eclosão da Segunda Guerra Mundial frustrou a ideia dos anos entre guerras de prevalência das normas e dos princípios no sistema internacional e mesmo depois do seu ocaso, o poder e os interesses nacionais remanesceram como a base das relações internacionais no mundo bipolar da Guerra Fria, não obstante a significativa produção normativa nesse período, a exemplo do direito do mar e dos direitos humanos, todavia, constantemente desrespeitados, o que tornou marginal os efeitos do direito internacional durante a Guerra Fria (SORNARAJAH, 1997, p. 32; SPIRO, 2000, p. 576-577).

Assim, depois da Segunda Guerra Mundial, os estudos dos teóricos das relações internacionais e do direito internacional foram influenciados pelo "desafio realista", isto é, o ceticismo de autores chamados de realistas "estruturais"3 ou "neorrealistas"4 sobre a relevância do direito para o sistema internacional. Considerável número de proeminentes estudiosos enquadra-se no campo do realismo estrutural, a exemplo de Edward H. Carr (2001), Hans Morgenthau (2003), ${ }^{5}$ George Kennan

\footnotetext{
${ }^{1} \mathrm{O}$ autor afirma que a base do Estado são as armas e as leis, contudo, inexistem "boas leis" sem "boas armas".

${ }^{2}$ Finda a Primeira Guerra Mundial, os acadêmicos das relações internacionais tiveram, descaradamente, a intenção de reformar o mundo. As preocupações e a abordagem dos estudiosos das relações internacionais tiveram uma inclinação acentuadamente normativa. A aparente irrelevância dos seus trabalhos para melhorar e reverter as crises políticas e econômicas internacionais dos anos 1930 fez com que essa epistemologia fosse questionada (JACOBSON, 1982, p. 319).

${ }^{3}$ Para as pretensões desta pesquisa, realistas clássicos e realistas estruturais ou neorrealistas serão igualmente considerados realistas.

${ }^{4}$ Os realistas estruturais são frequentemente referidos como neorrealistas, entretanto, há quem distinga o neorrealismo como sendo a teoria articulada por Kenneth Waltz do realismo estrutural como uma ampla família de teorias sistêmicas.

${ }^{5} \mathrm{O}$ autor dedica um capítulo aos "Problemas Principais do Direito Internacional", considerado um direito primitivo, fraco e dependente da distribuição de poder entre os
} 
$(1951)^{6}$ e, mais recentemente, ${ }^{7}$ Kenneth Waltz (1979) $)^{8}$ e Raymond Aron (2002). Eles retomaram a tradição realista e questionaram o pensamento internacionalista liberal wilsoniano, de que a democracia poderia vencer a guerra, ${ }^{9}$ e do "primado do direito" nas relações internacionais, ou seja, a possibilidade das normas e das instituições internacionais, a exemplo das Nações Unidas, ${ }^{10}$ regularem, efetivamente, o comportamento estatal. Destarte, reagiram com a ideia de polaridade entre direito e poder, domínio interno e internacional, aspiração normativa e descrição positiva, cooperação e conflito, ${ }^{11}$ idealismo e realismo (ACEVES, 1997, p. 227-228; BEDERMAN, 2001, p. 469-470; BURLEY, 1993, p. 205-207).

Estados, portanto, capaz de influenciar os comportamentos estatais apenas marginalmente. ${ }^{6} \mathrm{O}$ autor é conhecido por criticar o que chamou de "discurso legalista-moralista" das relações internacionais, ou seja, a possibilidade de normas internacionais limitarem a ação dos Estados em um sistema internacional caótico, por isso, uma retórica incapaz de identificar o significado dos problemas políticos e as fontes da instabilidade internacional. ${ }^{7}$ É válido ao menos mencionar outros importantes nomes: John Herz, Morton Kaplan, Robert Gilpin, Reinhold Niebuhr, Joseph M. Grieco, Robert J. Lieber e John J. Mearsheimer.

${ }^{8} \mathrm{O}$ autor, talvez o mais destacado entre todos, sequer analisa as normas internacionais.

${ }^{9} \mathrm{O}$ termo mais utilizado pelos detratores desse pensamento é "legalismo democrático".

${ }^{10}$ Embora alguns tenham visto a formação das Nações Unidas como uma iniciativa para a diminuição do poder e o fortalecimento do direito nas relações internacionais, outros a viram como instrumento a serviço dos interesses dos Estados hegemônicos. Assim, até hoje, a Organização das Nações Unidas (ONU) é um campo de batalha entre os que vislumbram o estabelecimento do império do direito internacional por meio da organização e os que acreditam ser a instituição utilizada pelos Estados mais fortes para alcançarem os seus objetivos (SORNARAJAH, 1997, p. 34).

${ }^{11}$ Em contrapartida, é importante evitar o engano comum de assumir que as teorias materialistas dizem respeito aos conflitos, enquanto as teorias culturais, à cooperação. $\mathrm{O}$ valor de argumentos analiticamente neutros independe da extensão em que os Estados cooperam (JEPPERSON; WENDT; KATZENSTEIN apud KATZENSTEIN, 1996. p. 36). Como os próprios realistas incessantemente destacam, há uma relação dialética entre cooperação e conflito, por isso, ambos os conceitos não podem ser compreendidos separadamente. Nesse sentido, a despeito do importante papel de algumas características da motivação humana - tais como altruísmo, idealismo, honra pessoal, razões comuns, normas internalizadas ou crenças compartilhadas a partir de um conjunto de valores incorporados culturalmente - a cooperação internacional pode ser entendida sem referência a nenhuma delas, uma vez que nem sempre se trata de um processo benigno, do ponto de vista ético. Por exemplo, muitas vezes, alguns Estados ricos exploram, 
Para o realismo, um direito internacional sem mecanismos coerciti$\operatorname{vos}^{12}$ não era apenas algo inócuo, porém, principalmente danoso, por isso, a obsessão pela relevância levou os realistas a ignorarem (ou, talvez, irem além de) quaisquer referências normativas (mundo jurídico), em prol de preocupações descritivas (mundo real) (HATHAWAY, 2005, p. 470; BRUNNÉE; TOOPE, 2000, p. 23; ROCHESTER, 1986, p. 812).

Num primeiro momento, os argumentos realistas podem parecer cínicos, contudo, analisados com mais cuidado, é válida a advertência de que a cooperação internacional não se trata de um ato de benemerência, tampouco a ação estatal no plano internacional é neutra e desinteressada. É enganoso pensar que o realismo desconsidera a existência de instituições internacionais, ao contrário, elas são importantes instrumentos dos Estados com maiores recursos materiais. Desse modo, a cooperação nada mais é do que a outra face do conflito. Portanto, não há de se questionar um realista sobre se as normas internacionais influenciam o comportamento dos Estados, porém, de acordo com os interesses de quais Estados determinam as condutas internacionais.

A perspectiva realista concentra-se principalmente no papel dos Estados nas relações internacionais, e não nas ações das instituições internacionais, como os atores dominantes (embora não exclusivos), unitários, racionais e egoístas das relações internacionais, e como os sujeitos primários do direito internacional (ELVY, 2012, p. 81; FRISCHMANN, 2003, p. 702; GUZMAN, 2002, p. 1836; HATHAWAY, 2005, p. 477).

Fundamentalmente, os defensores dessa escola de pensamento alegam que os fatores materiais, tais como recursos militares e financeiros, importam muito mais do que os fatores não materiais, tais como as normas e as instituições internacionais. Consequentemente, os Estados po-

conjuntamente, recursos dos Estados pobres, outros formam alianças de agressão e, até mesmo, as indústrias nacionais influenciam os seus governos a protegê-las da concorrência de produtos estrangeiros mais eficientes (KEOHANE, 1988, p. 380).

12 Para os realistas, as instituições influenciam os comportamentos estatais, fundamentalmente, por meio de pressão ou coerção (GOODMAN; JINKS, 2003b, p. 1.751). As instituições jurídicas sozinhas não são suficientes. É necessário que os principais Estados utilizem o poder econômico ou militar para produzirem mudanças de comportamento, com os riscos inerentes a essas táticas (ABBOTT, 2004, p. 153). 
derosos usam várias estratégias - muitas vezes sutis - para moldar os regimes jurídicos internacionais, consoante os seus interesses e, enfim, é a distribuição e o equilíbrio de poder entre os Estados que determina, verdadeiramente, os seus comportamentos (ARMSTRONG; FARRELL; LAMBERT, 2012, p. 79; GOODMAN; JINKS, 2004, p. 634; HATHAWAY; LAVINBUK, 2006, p. 1.430; ABBOTT, 2005, p. 31).

A questão é o que define o pressuposto básico do sistema internacional. Apesar do Estado hobbesiano da sociedade internacional, a perspectiva teórica do paradigma realista não exclui da estrutura e do funcionamento do sistema internacional as políticas de coordenação e cooperação internacional mediante normas internacionais, ${ }^{13}$ possíveis e até recorrentes, desde que sejam, por um lado, estabelecidas e aplicadas pelos Estados mais fortes e, por outro, cumpridas, compulsoriamente, pelos Estados mais fracos, isto é, as realidades políticas dos Estados mais poderosos definirão os termos de cooperação, como uma resposta instrumental ${ }^{14}$ das lutas pelo poder, sem absolutamente nenhum mérito intrínseco ou preocupação com o benefício do próprio sistema. Dessa forma, os princípios, as normas, as regras e os procedimentos de tomada de decisão afetam os comportamentos, ${ }^{15}$ porém, de acordo com a distribuição de poder,

${ }^{13}$ Apesar dos intermináveis debates sobre o dilema teórico das obrigações jurídicas internacionais, simultaneamente, derivarem do e prevalecerem sobre o Estado, os realistas aceitam que o direito e o poder interagem de alguma forma e, assim, o direito internacional produz algum efeito sobre o comportamento dos Estados (BURLEY, 1993, p. 208).

${ }^{14}$ Os instrumentistas identificam um caminho causal a partir dos interesses subjacentes dos Estados até os seus comportamentos (KEOHANE, 1999, p. 376).

${ }^{15}$ Esta definição de "regimes", de autoria de Krasner (q982, p. 186-189), é a mais reproduzida na literatura das relações internacionais. Detalhadamente, corresponde à combinação dos seguintes elementos (implícitos ou explícitos), em torno dos quais as expectativas dos atores convergem em determinada área das relações internacionais: (i) princípios, por meio da aceitação de um fato, dos nexos de causalidade e da retidão de comportamento; (ii) normas, no sentido de padrões de comportamento definidos em termos de direitos e obrigações; (iii) regras, como prescrições específicas decorrentes de uma ação; (iv) procedimentos de tomada de decisão, quando práticas predominantes na formação e implementação da vontade coletiva. Os princípios e as normas definem as características básicas de um regime, com as quais as regras e os procedimentos de tomada de decisão devem se adequar. Dessa maneira, as mudanças nas regras e nos procedimentos 
fundados no interesse próprio e egoísta, ${ }^{16}$ ou seja, nos valores nacionais dos Estados hegemônicos (KINGSBURY, 1998, p. 350-351; ABBOTT, 2004, p. 133; MUSHKAT, 2010, p. 499 e 501; KRASNER, 1982, p. 194195 e 199).

Nessa medida, os realistas são céticos. ${ }^{17}$ A visão cética dos realistas não reside na ausência de influência das normas das organizações internacionais sobre os comportamentos estatais, mas sim na dependência delas do poder internacional, ou seja, os Estados poderosos têm menos necessidade de e mais razão para resistir às normas das organizações internacionais que destoem de seus interesses nacionais (GOLDSMITH; POSNER, 1999, p. 1.203; ABBOT; SNIDAL, 2000, p. 448).

A concepção realista não vislumbra a inexistência normativa internacional, tampouco um cenário necessariamente negativo do sistema internacional, senão a formulação e a aplicação das normas internacionais a partir do poder dos Estados mais importantes e a ação desses Estados a partir de suas necessidades e de seus interesses. Consequentemente, os regimes internacionais servem a um propósito instrumental, qual seja, as preferências dos Estados mais fortes do sistema internacional (ABBOTT, 2004, p. 152-153; AREND, 1998, p. 115; HATHAWAY, 2005, p. 478; GOLDSMITH; POSNER, 1999, p. 1120; KRASNER, 2000, p. 93; SLAUGHTER, 1995, p. 507; ZURN In: JOERGES, 2005, p. 04).

Nessa esteira, não se deve olvidar que sem poder, não há direito. Aliás, em todo sistema social os atores mais fortes impõem os seus interesses sobre os mais fracos. Destarte, ao invés de resistir ao papel do poder na composição do direito internacional, deve-se aceitar a capacidade dos Estados poderosos como um elemento fundamental da elaboração, da execução e do cumprimento das normas internacionais. Entretanto, se

de tomada de decisão implicam as mudanças dentro de um regime, enquanto as mudanças nos princípios e nas normas implicam a mudança do próprio regime.

${ }^{16}$ A premissa do interesse próprio, ao contrário de fundamentar as práticas imorais, explica por que os indivíduos cumprem as normas (ROEMER, 2000, p. 16 - 17).

${ }^{17}$ Outrossim, os céticos consideram-se realistas. Para eles, o direito internacional nada mais é do que aquilo que os Estados fazem de fato. Consoante um modelo descritivo, explicam os comportamentos a partir dos interesses próprios de cada Estado (PURVIS, 1991, p. 84, nota 19 e p. 85). 
para o realismo a base das normas internacionais não é o consenso ou o interesse mútuo, senão os interesses de poder dos Estados dominantes, isso não significa que o sistema jurídico internacional seja simplesmente refém da vontade desses Estados, porém, que precisa conciliar-se com ela (COGAN, 2006, p. 207; GILPIN, 1981, p. 35-36).

Em síntese, a estrutura institucional do sistema internacional traduz a distribuição de poder entre os Estados, assim, a cooperação internacional somente avança quando há equilíbrio de poder e as normas internacionais expressam os interesses dos Estados poderosos. Portanto, a cooperação internacional não beneficia necessariamente os Estados mais fracos, os únicos que cumprem as normas internacionais mesmo quando contrárias aos seus interesses (STEINBERG, 2002, p. 346; SLAUGHTER, 1995, p. 507; ALKOBY, 2003, p. 65).

O ceticismo realista está em não conceber o direito internacional como algo que vá muito além do poder dos Estados. Consequentemente, numa sociedade internacional sem equilíbrio de poder, o direito internacional é inócuo quando busca coordenar o comportamento dos Estados a partir de categorias como consentimento, reciprocidade, reputação, legitimidade ou justiça. Para o realismo, deve-se estar ciente que há uma clara separação entre os Estados que escrevem as normas internacionais e os que as cumprem e, a partir daí, fazer um bom desse fato.

Daí que como corolário os realistas acreditam que se as relações de poder entre os Estados forem alteradas, o direito internacional também será, portanto, os regimes, as instituições e as normas não são variáveis independentes, ou seja, não têm força causal independente nas relações internacionais, em outras palavras, não são variáveis causais básicas, porquanto não têm impacto independente sobre os comportamentos dos Estados, ao contrário, afetam as perspectivas de cooperação internacional apenas marginalmente, pois são determinadas pelos interesses dos Estados poderosos (AREND, 1998, p. 115; ALKOBY, 2003, p. 65; KREPS; AREND, 2006, p. 336; KRASNER, 1982, p. 190 e 194; GUZMAN, 2002, p. 1837; ABBOTT, 2004, p. 133; GRIECO, 1988, p. 488). 
A partir de uma ótica instrumental, não há uma força normativa internacional independente, senão uma lógica de custo e benefício que define o direito internacional a partir dos interesses dos Estados dominantes. Para o realismo, as normas internacionais são tão afetadas por fatores estruturais do sistema internacional - em particular, o poder político, econômico e militar de um Estado - quanto os comportamentos estatais (GOLDSMITH, 2000, p. 963; RATNER, 2000, p. 648).

Dessa forma, se o direito internacional alterar os custos e os benefícios pode influenciar as condutas estatais, porém, a dinâmica causal remanesce imutável e determinada pelos interesses dos Estados mais fortes. Assim, os realistas questionam a relevância de um direito que não é direito, mas um epifenômeno, um títere dos poderes, interesses e preferências dos Estados. Debruçam-se sobre a falta de um sistema judiciário independente com o poder de obrigar os Estados e concluem que o direito internacional é apenas um conjunto de limitações autoimpostas, em outras palavras, um "direito de fachada" (GOODMAN; JINKS, 2003a, p. 181; ABBOT; SNIDAL, 2000, p. 422; LEVIT, 2004, p. 95; SORNARAJAH, 1997, p. 31).

Numa visão estritamente realista, os comportamentos estatais não decorrem do caráter jurídico e da justificação moral dos compromissos e das instituições internacionais, senão da ameaça ou efetiva exclusão dos benefícios - e, em alguns casos, até mesmo da aplicação de sanções concedidos aos Estados mais fracos pelos Estados mais fortes. ${ }^{18}$ Os mecanismos coercitivos são de tão pouco valor para os Estados menos poderosos quanto os mecanismos de reciprocidade o são para os Estados

${ }^{18} \mathrm{O}$ regime jurídico ambiental demonstra a concepção realista de incentivos e sanções como os principais mecanismos para combater a tendência ao não cumprimento das normas internacionais, por óbvio, pelos Estados mais fracos (MUSHKAT, 2010, p. 512). Para a maioria dos acadêmicos das relações internacionais, os recursos disponíveis aos Estados determinam os incentivos que podem oferecer, bem como as penalidades que podem ameaçar impor ou impor efetivamente, por exemplo, apenas por meio do poder coercitivo estatal é possível mobilizar recursos tais como os pagamentos em dinheiro do Fundo de Ozônio e as sanções do Tratado de Não-Proliferação Nuclear, portanto, o poder é capaz de definir as agendas e de moldar a interpretação e o desenvolvimento de instituições jurídicas internacionais (HAFNER-BURTON; VICTOR; LUPU, 2012, p. 83 - 84). 
mais poderosos, ${ }^{19}$ o que explica a tendência dos Estados dominantes a descumprirem as suas obrigações internacionais (WATTS, 2009, p. 370; KEOHANE, 1992, p. 177-178).

Nessa esteira, diante da presunção realista de que os Estados são avessos a cooperar, o cumprimento das normas internacionais ocorre em função dos cálculos de custo e benefício, isto é, quanto mais coercitivos forem os mecanismos, maior será a indução ao cumprimento das normas internacionais, em outras palavras, a conformidade às normas internacionais dá-se quando imposta pelos Estados dominantes por meio de estímulos externos, ou seja, pressão pelo descumprimento ou recompensa pelo cumprimento. Portanto, o cumprimento é irregular e varia de acordo com os interesses da hegemonia, ${ }^{20}$ sendo melhor pensar em níveis de cumprimento (HAAS, 1997, p. 26; RAUSTIALA, 2002, p. 78; SHANY, 2012, p. 262).

${ }^{19}$ A reciprocidade fracassará em induzir o cumprimento das normas internacionais se a resposta à violação não for capaz de atingir o violador (GUZMAN, 2008, p. 45).

${ }^{20} \mathrm{O}$ pensamento de Antonio Gramsci sobre a relação entre dominantes e dominados fundou uma teoria das relações internacionais que vê na sociedade internacional a busca da manutenção da posição dominante de um "bloco histórico hegemônico", por meio da articulação entre a coerção dos mais fortes e o consentimento dos mais fracos. Para o gramscianismo, a dominação diz respeito a um conjunto de valores (desde o final da Segunda Guerra Mundial, esses valores estão ligados ao Liberalismo e incluem a liberdade, a democracia e o capitalismo) e é possível porque os dominantes criam uma "sensação de normalidade", responsável pela imposição do cumprimento de normas internacionais que refletem os interesses da minoria hegemônica. Essa combinação, sutil e não tão sutil, entre coerção e consentimento, produz nos Estados dominados um desconforto em descumprir as normas internacionais, fazendo-as parecer legítimas. Para alguns autores, as ideias de Gramsci são uma forma de realismo, contudo, o realismo concentra-se em relações de poder, enquanto o gramscianismo, nas relações ideológicas, consoante uma perspectiva marxista. Para outros autores, como Gramsci enfatiza a importância das fontes de legitimação das ideias e das ideologias, a sua teoria é mais próxima dos trabalhos construtivistas do que de estudos materialistas do marxismo (KATZENSTEIN; KEOHANE; KRASNER, 1998, p. 665). Ademais, Gramsci vislumbra um papel forte para o direito como um meio que estabelece a ordem burguesa e subordina as demais classes sociais. Outra diferença digna de nota é entre os elementos de coerção e consentimento identificados por Gramsci no sistema internacional e a construção do direito internacional a partir exclusivamente do consentimento dos Estados de acordo com o positivismo jurídico. Nesse sentido, o gramsciano é útil para se entender a natureza das fontes do direito internacional e explicar como os Estados fortes tanto dominam o processo de produção e aplicação coercitiva das normas internacionais (dois níveis de 
Se o realismo não desconsidera a existência do direito internacional, tampouco dimensiona o seu verdadeiro tamanho. Quando propugnam que o direito internacional não é um fenômeno autônomo com força causal independente, ironicamente, os realistas distanciam-se da realidade internacional. O equívoco do realismo está em interpretar o direito e a imposição coercitiva do direito como se fosse a mesma coisa.

Entretanto, a teoria realista admite que o cumprimento do direito internacional é bastante difundido, embora atribua isso, além das relações de poder, aos interesses convergentes das potências internacionais, portanto, as condutas estatais não mudam no plano internacional, apenas evidenciam posturas convergentes na forma de normas internacionais, que cumprem um papel instrumental na imposição de sanções positivas e negativas (SIMMONS, 1998, p. 76-77 e 79; ALKOBY, 2008, p. 192-193).

A escola realista baseia-se na premissa de que os desenvolvimentos normativos e institucionais ${ }^{21}$ são aqueles com os quais os Estados poderosos podem conviver e que têm um maior interesse em respeitar, destarte, o cumprimento das normas internacionais depende da vontade desses Estados (GOODMAN; JINKS, 2004, p. 634; HALLING, 2009, p. 259; KINGSBURY, 1998, p. 351 e 370).

Por isso, muitas vezes, o discurso dos Estados mais fortes é o inverso de suas ações e apenas falsifica os fatos. Na verdade, os Estados poderosos não hesitam, tampouco se constrangem, em abandonar ${ }^{22}$ as prescri-

hegemonia), quanto monopolizam a prática jurídica dos tribunais internacionais (o que revela a parcialidade ostensiva do e inerente ao sistema internacional), ao mesmo tempo em que garantem o consentimento dos Estados fracos e, principalmente, como isso afeta o desenvolvimento do direito internacional (FRY, 2008, p. 308-313, 320, 322, 324 e 335 336).

21 Em geral, os Estados poderosos aceitam as decisões majoritárias apenas nas organizações internacionais juridicamente competentes para produzir "direito brando", a fim de não se verem obrigados a terem de cumprir algo que não lhes favoreça, enquanto, nas organizações internacionais capazes de produzir "direito rígido", propugnam que as decisões sejam tomadas por consenso e desde que haja uma relação direta entre poder, interesses, regras de votação e resultados (STEINBERG, 2002, p. 340 e 346).

${ }^{22}$ Até mesmo os menos importantes arranjos internacionais são facilmente desconsiderados quando mudam a balança de poder ou a percepção de interesse nacional (ou ambos) entre aqueles Estados com que negociam (STRANGE, 1982, p. 487). 
ções normativas internacionais sempre que mais conveniente fazê-lo, ou seja, quando não mais servem aos seus interesses (GOLDSMITH, 2000, p. 963; HENKIN, 1979. p. 43; YOUNG, 1986, p. 119; AREND, 1998, p. 115-116).

À parte isso, consoante o realismo, em um mundo anárquico, quando os Estados poderosos cumprem o direito internacional, fazem-no por mera coincidência entre o conteúdo das normas internacionais e os seus interesses próprios, normalmente derivados de políticas de poder, ou seja, porque já o fariam de qualquer maneira, jamais pela força do compromisso em si (ABBOTT, 2004, p. 133; LEVIT, 2004, p. 95; GUZMAN, 2002, p. 1.837).

Os Estados dominantes participam dos arranjos institucionais dos regimes jurídicos internacionais, quando compatíveis com os seus interesses nacionais imediatos, isto é, cumprem o direito internacional enquanto atende a esses interesses, e muitas vezes, ambos são perfeitamente compatíveis (GINSBURG; MCADAMS, 2004, p. 1.234; YOUNG, 1986, p. 119; AREND, 1998, p. 132).

Finalmente, considerando que para o realismo os Estados buscam o poder para garantirem a própria segurança no sistema internacional, são esperadas do direito internacional menos restrições sobre os comportamentos estatais pertinentes, por exemplo, ao uso da força militar, ${ }^{23}$ em outras palavras, especialmente nos domínios da "alta política", ${ }^{24}$ os

\footnotetext{
${ }^{23} \mathrm{O}$ cumprimento é maior na área de direitos humanos, menor na ambiental, seguida pela comercial e, por fim, a de segurança (HAAS, 1997, p. 26).

${ }^{24}$ É associada à teoria realista das relações internacionais, a distinção entre "alta política", geralmente definida como aquela relativa às questões militares e de segurança nacional, e "baixa política", referindo-se às demais questões, tais como comércio, meio ambiente e direitos humanos. Contudo, advirta-se que "alta política" e "baixa política" não são categorias absolutas, ao contrário, são polos em uma reta. Algumas questões estão exclusivamente de um ou do outro lado desse espectro, outras aparecem em diversos pontos dessa linha, pois Estados diferentes (ou os mesmos Estados em momentos diferentes) podem considerar as mesmas questões de maneira distinta (AREND, 1998, p. 122).
} 
realistas são céticos sobre o primado do direito ${ }^{25}$ e os processos jurídicos nas relações internacionais, ou seja, sobre a capacidade das normas internacionais confrontarem os interesses nacionais. Consequentemente, para um realista, não é fortuito o fato das mesmas questões políticas sobre as quais os regimes exercem um papel central no âmbito nacional estarem marginalizadas no âmbito internacional (AREND, 1998, p. 114; IRISH; KU; DIEHL, 2013, p. 380; STRANGE, 1982, p. 487; SIMMONS, 1998, p. 80).

A avaliação negativa realista pertinente à cooperação internacional advém do fato que, nesse mundo anárquico e hobbesiano, a ausência de um "governo mundial" - isto é, de uma autoridade central capaz de elaborar, aplicar e monitorar o cumprimento das normas de forma coercitiva - leva os Estados a buscarem maximizar a própria segurança, o que os conduz, inevitavelmente, ao conflito (MUSHKAT, 2010, p. 498; KREPS; AREND, 2006, p. 337).

Assim, conforme o realismo, o cumprimento do direito internacional depende de uma relação de conveniência, convergência, coincidência e compatibilidade entre os interesses dos Estados fortes e as normas internacionais, excluídas as questões fundamentais de segurança internacional, necessárias à própria existência dos Estados e em que sequer há essa espécie de simulacro de "império da lei internacional".

\section{Conclusão}

Os realistas consideram os regimes e as instituições internacionais como elementos úteis para a estabilidade das relações de cooperação do sistema internacional, desde que, sejam criados e impostos, sem reciprocidade, a partir das realidades dos Estados poderosos, nas searas da "alta política", ou seja, ferramentas forjadas pelo interesse próprio e egoísta dos Estados hegemônicos em busca de maximizarem segurança internacional ("dilema da segurança"). Essa premissa básica do cumprimento

${ }^{25}$ Em sentido contrário: O maior desafio para o primado do direito internacional é o de melhorar a adesão dos Estados às normas mesmo em áreas tradicionalmente consideradas pelos realistas como imunes à regulamentação jurídica (MOORE, 1999, p. 884). 
das normas internacionais pelos Estados, conforme o paradigma realista, não serve para justificar condutas internacionais imorais, senão para explicá-las. Tampouco isso é algo necessariamente ruim, obviamente, de acordo com quais sejam as preferências do hegemon.

Desse modo, consoante o realismo, o direito internacional é um títere do poder, um mero epifenômeno, isto é, um "direito de fachada", fraco, composto por um conjunto de limitações autoimpostas pelos Estados. Para os realistas, o fato do direito ser manipulado pelo poder é uma característica instrumental de todo sistema social, não apenas do internacional. Isso faz, inclusive, que o cumprimento das normas seja recorrente no cenário internacional, embora se deva às relações de conveniência ou à mera convergência entre os interesses dos Estados fortes e o direito internacional. Entretanto, esse raciocínio confunde o direito com a aplicação coercitiva do direito e, ao diminuir a importância do direito internacional, paradoxalmente, distancia os realistas da realidade do sistema internacional que pretendem analisar.

\section{Referências}

ABBOTT, Kenneth W. International relations theory, international law, and the regime governing atrocities in international conflicts. Studies in Transnational Legal Policy, [S.l.], v. 36, p. 127-158, 2004.

ABBOTT, Kenneth W. Toward a richer institutionalism for international law and policy. Journal of International Law and International Relations, [S.l.], v. 1, n. 1-2, p. 9-34. 2005.

ABBOTT, Kenneth W.; SNIDAL, Duncan. Hard and soft law in international governance. International Organization, [S.l.], v. 54, p. 421-456, 2000.

ACEVES, William J. Institutionalist theory and international legal scholarship. American University Journal of International Law and Policy, [S.l.], v. 12, n. 2, p. 227-266, 1997. 
ALKOBY, Asher. Non-state actors and the legitimacy of international environmental law. Non-State Actors and International Law, [S.l.], v. 3, n. 1, p. 23-98, 2003.

ALKOBY, Asher. Theories of compliance with international law and challenge of cultural difference. Journal of International Law and International Relations, [S.l.], v. 4, p. 151-198, 2008.

AREND, Anthony Clark. Do legal rules matter? international law and international politics. Virginia Journal of International Law, [S.l.], v. 38, p. 107-154, 1998.

ARMSTRONG, David; FARRELL, Theo; LAMBERT, Hélène.

International law and international relation. 2. ed. Cambridge:

Cambridge University Press, 2012. 353 p.

ARON, Raymond. Paz e guerra entre nações. Trad. Sergio

Bath. Brasília, DF: Universidade de Brasília, 2002. 928 p.

BEDERMAN, David J. Constructivism, positivism, and empiricism in international law. Georgetown Law Journal, [S.l.], v. 89, n. 2, p. 469500, 2001.

BOYLE, Francis A. World politics and international law. Durham: Duke University Press, 1985. 366 p.

BRUNNÉE, Jutta; TOOPE, Stephen J. International law and constructivism: elements of an interactional theory of international law. Columbia Journal of Transnational Law, [S.l.], v. 39, n. 1, p. 19-74, 2000 .

BURLEY, Anne-Marie Slaughter. International law and international relations theory: a dual agenda. American Journal of International Law, [S.l.], v. 87, n. 2, p. 205-239, 1993.

CARR, Edward Hallett. Vinte anos de crise, 1919-1939: uma introdução ao estudo das relações internacionais. Trad. Luiz Alberto Figueiredo Machado. 2. ed. Brasília, DF: Universidade de Brasília, 2001. 312 p.

COGAN, Jacob Katz. Noncompliance and the international rule of law. The Yale Journal of International Law, [S.l.], v. 31, p. 189-210. 2006. 
ELVY, Stacy-Ann. Theories of state compliance with international law: assessing the african union's ability to ensure state compliance with the african charter and constitutive act. Georgia Journal of International and Comparative Law, [S.l.], v. 41, n. 1, p. 75-156, 2012.

FRISCHMANN, Brett. A dynamic institutional theory of international law. Buffalo Law Review, [S.l.], v. 51, p. 679-809, 2003.

FRY, James D. Legitimacy push: towards a gramscian approach to international law. UCLA Journal of International Law and Foreign Affairs, [S.l.], v. 13, n. 2, p. 308-336, 2008.

GILPIN, Robert. War and change in world politics. Cambridge: Cambridge University Press, 1981. 272 p.

GINSBURG, Tom; MCADAMS, Richard H. Adjudicating in anarchy: an expressive theory of international dispute resolution. William and Mary Law Review, [S.l.], v. 45, n. 4, p. 1.229-1.340, 2004.

GINSBURG, Tom; SHAFFER, Gregory. How does international law work? what empirical research shows. Minnesota Legal Studies Research, [S.l.], Paper n. 9-54, p. 1-26, 2009.

GOLDSMITH, Jack. Sovereignty, international relations theory, and international law. Stanford Law Review, [S.l.], v. 52, p. 959-986, 2000. GOLDSMITH, Jack; POSNER, Eric A. A theory of customary international law. The University of Chicago Law Review, [S.l.], v. 66, p. 1.113-1.211, 1999.

GOODMAN, Ryan; JINKS, Derek. How to influence states: socialization and international human rights law. Duke Law Journal, [S.l.], v. 54, p. 621-704, 2004.

GOODMAN, Ryan; JINKS, Derek. Measuring the effects of human rights treaties. European Journal of International Law, [S.l.], v. 14, p. 171-183, 2003.

GOODMAN, Ryan; JINKS, Derek. Toward an institutional theory of sovereignty. Stanford Law Review, [S.l.], v. 55, n. 5, p. 1.749-1.788, 2003. 
GRIECO, Joseph M. Anarchy and the limits of cooperation: a realist critique of the newest liberal institutionalism. International Organization, [S.l.], v. 42, n. 3, p. 485-507, 1988.

GUZMAN, Andrew T. A compliance-based theory of international law. California Law Review, [S.l.], v. 90, p. 1.823-1.887, 2002.

GUZMAN, Andrew T. How international law works: a rational choice theory. Oxford: Oxford University Press, 2008. 260 p.

HAAS, Peter M. Why comply, or some hypotheses in search of an analyst. Studies in Transnational Legal Policy, [S.l.], v. 29, p. 21-48, 1997.

HAFNER-BURTON, Emilie M.; VICTOR, David G.; LUPU, Yonatan. Political science research on international law: the state of the field. The American Journal of International Law, [S.l.], v. 106, p. 47-97, 2012.

HALLING, Matt. A law of no gods, no masters: developing and defending a participatory legal system. Hastings International and Comparative Law Review, [S.l.], v. 32, n. 1, p. 237-270, 2009.

HATHAWAY, Oona A. Between power and principle: a political theory of international law. Yale Law School Legal Scholarship Repository, [S.l.], p. 469-536, jan. 2005.

HATHAWAY, Oona A.; LAVINBUK, Ariel N. Rationalism and revisionism in international law. Harvard Law Review, [S.l.], v. 119, n. 5, p. 1.404-1.444, 2006.

HENKIN, Louis. How nations behave: law and foreign policy. 2. ed. New York: Columbia University, 1979. 400 p.

HOBBES, Thomas. Leviatã: ou, a matéria, forma e poder de um Estado eclesiástico e civil. Trad. Rosinna D’Angina. 2. ed. São Paulo: Ícone, 2003. 487 p.

IRISH, Adam; KU, Charlotte; DIEHL, Paul F. Bridging the international law-international relations divide: taking stock of progress. Georgia Journal of International and Comparative Law, [S.l.], v. 41, n. 2, p. 357-388, 2013. 
JACOBSON, Harold K. The global system and the realization of human dignity and justice. International Studies Quarterly, [S.l.], v. 26, n. 3, p. 315-332, 1982.

JEPPERSON, Ronald L.; WENDT, Alexander; KATZENSTEIN, Peter J. Norms, identity, and culture in national security. In: KATZENSTEIN, Peter J. (coord.). The culture of national security. New York: Columbia University Press, 1996. p. 33-75.

KATZENSTEIN, Peter J.; KEOHANE, Robert O,; KRASNER, Stephen D. International organization and the study of world politics. International Organization, [S.l.], v. 52, n. 4, p. 645-685, 1998.

KENNAN, George Frost. American diplomacy: 1900-1950. New York: Mentor, 1951. 144 p.

KEOHANE, Robert O. Compliance with international commitments: politics within a framework of law. American Society of International Law Proceedings, [S.l.], v. 86, p. 176-179, 1992.

KEOHANE, Robert O. International institutions: two approaches. International Studies Quarterly, [S.l.], v. 32, n. 4, p. 379-396, 1988.

KEOHANE, Robert O. International relations and international law: interests reputation, institutions. American Society of International Law Proceedings, [S.l.], v. 93, p. 375-379, 1999.

KINGSBURY, Benedict. The concept of compliance as a function of competing conceptions of international law. Michigan Journal of International Law, [S.l.], v. 19, p. 345-372, 1998.

KRASNER, Stephen D. International law and international relations: together, apart, together? Chicago Journal of International Law, [S.l.], v. 1, n. 1, p. 93-100, 2000.

KRASNER, Stephen D. Structural causes and regime consequences: regimes as intervening variables. International Organization, [S.l.], v. 36, n. 2, p. 185-205, 1982.

KREPS, Sarah Elizabeth; AREND, Anthony Clark. Why states follow the rules: toward a positional theory of adherence to international legal 
regimes. Duke Journal of Comparative \& International Law, [S.l.], v. 16, n. 2, p. 331-411, 2006.

LEVIT, Janet Koven. The dynamics of international trade finance regulation: the arrangement on officially supported export credits. Harvard International Law Journal, [S.l.], v. 45, n. 1, p. 65-181, 2004. MAQUIAVEL, Nicolau. O príncipe. Trad. Maria Júlia Goldwasser. 4. ed. São Paulo: Martins Fontes, 2011. 197p.

MOORE, John Norton. Enhancing compliance with international law: a neglected remedy. Virginia Journal of International Law, [S.l.], v. 39, n. 4, p. 881-1.016, 1999.

MORGENTHAU, Hans Joachim. A política entre as nações: a luta pelo poder e pela paz. Trad. Oswaldo Biato. Brasília, DF: Universidade de Brasília, 2003. 1.093 p.

MUSHKAT, Roda. Compliance with international environmental regimes: chinese lessons. William \& Mary Environmental Law and Policy Review, [S.l.], v. 34, n. 2, p. 493-542, 2010.

PURVIS, Nigel. Critical legal studies in public international law.

Harvard International Law Journal, [S.l.], v. 32, n. 1, p. 81-128, 1991. RATNER, Steven R. Does international law matter in preventing ethnic conflict? New York University Journal of International Law and Politic, [S.l.], v. 32, p. 591-698, 2000.

RAUSTIALA, Kal. The architecture of international cooperation: transgovernmental networks and the future of international law. Virginia Journal of International Law, [S.l.], v. 43, n. 1, p. 1-92, 2002.

ROCHESTER, J. Martin. The rise and fall of international organization as a field of study. International Organization, [S.l.], v. 40, n. 4, p. 777 813, 1986.

ROEMER, A. Introducción al análisis económico del derecho. 2. ed. México: ITAM, 2000. 
SHANY, Yuval. Assessing the effectiveness of international courts: a goal-based approach. American Journal of International Law, [S.l.], v. 106, n. 2, p. 225-270, 2012.

SIMMONS, Beth A. Compliance with international agreements. Annual Reviews of Political Science, [S.l.], v. 1, p. 75-93, 1998.

SLAUGHTER, Anne-Marie. International law in a world of liberal states. European Journal of International Law, [S.l.], v. 6, n. 4, p. 503-538, 1995.

SORNARAJAH, M. Power and justice in international law. Singapore Journal of International \& Comparative Law, [S.l.], v. 1, n. 1, p. 2868, 1997.

SPIRO, Peter J. Globalization, international law, and the academy. New York University Journal of International Law and Politics, [S.l.], v. 32, n. 2, p. 567-590, 2000.

STEINBERG, Richard H. In the shadow of law or power? Consensusbased bargaining and outcomes in the GATT/WTO. International Organization, [S.l.], v. 56, n. 2, p. 339-374, 2002.

STRANGE, Susan. Cave! Hic dragones: a critique of regime analysis. International Organization, [S.l.], v. 36, n. 2, p. 479-496, 1982.

TUCÍDIDES. História da guerra do Peloponeso. Trad. Mário da Gama Kury. Brasília, DF; São Paulo: Universidade de Brasília; Imprensa Oficial de São Paulo: Instituto de Pesquisa de Relações Internacionais, 2001. 582 p.

WALTZ, Kenneth Neal. Theory of international politics. Boston, Mass.: Mcgraw-Hill, 1979. 251 p.

WATTS, Sean. Reciprocity and the law of war. Harvard International Law Journal, [S.l.], v. 50, n. 2, p. 365-434, 2009.

YOUNG, Oran R. International regimes: toward a new theory of institutions. World Politics, [S.l.], v. 39, n. 1, p. 104-122, 1986.

ZURN, Michael. Introduction: law and compliance at different levels. In: ZURN, Michael; JOERGES, Christian (coord.). Law and governance 
in postnational Europe: compliance beyond the nation-state. New York: Cambridge University Press, 2005. p. 1-39.

Fernando Lopes Ferraz Elias é Graduado em Direito pela Pontifícia Universidade Católica de São Paulo (1998). Graduado em Relações Internacionais pela Pontifícia Universidade Católica de São Paulo (1998). Mestre em Relações Internacionais pela Universidade do Sul de Santa Catarina (2002) e doutor em Direito pelo Centro Universitário de Brasília (2017). Professor universitário (desde 1999) e Coordenador de Curso (desde 2008). Experiência na área de Direito e Relações Internacionais, com ênfase em Direito Internacional.

E-mail: fernandoelias2006@hotmail.com

Endereço profissional: Centro Universitário de Brasília, Faculdade de Ciências Jurídicas e Sociais (FAJS). Quadra SEPN 707/907, Asa Norte, Brasilia, DF, Brasil. CEP: 70.790-075. 